\title{
Kombinasi Pompa Vakum Dengan Pompa Hidrolik Ram (Hidram)
}

\author{
${ }^{1}$ Maidi Saputra, ${ }^{2}$ Hendra Saputra. S \\ ${ }^{1}$ Dosen Teknik Mesin - Universitas Teuku Umar - Meulaboh \\ ${ }^{2}$ Mahasiswa Teknik Mesin - Universitas Teuku Umar - Meulaboh E-mail \\ :maidisaputra@utu.ac.id
}

\begin{abstract}
Abstrak
Air merupakan salah satu faktor yang sangat penting dan dibutuhkan dalam kehidupan makhluk hidup. Selain untuk pengembangan fisologis makhluk hidup, air juga menjadi input bagi beragam upaya atau kegiatan makhluk hidup dalam rangka menghasilkan sesuatu untuk kelangsungan hidupnya. Oleh karena itu, perlu dicari dan dikembangkan suatu model teknologi tepat guna, efisien, dan ekonomis sehingga dapat menyelesaikan permasalahan yang berkaitan dengan pemenuhan kebutuahan hidup manusia tersebut. Salah satu teknologi irigasi yang mulai dikembangkan adalah pompa hydrolic ram atau lazim disebut pompa hidram. Dalam perancangan pompa hidram, agar mempunyai efisiensi sebaik mungkin di perlukan penelitian terhahap komponen komponen utama pada pompa hidram tersebut. Dalam pebelitian ini dilakukan pengujian penggunaan variasi tabung udara dan panjang pipa masuk untuk mendapatkan ukuran volume tabung udara dan panjang pipa pemasukan sehingga mempunyai efisiensi yang paling baik. Penelitian ini dilakukan di Laboratorium SMK 1 Sama Tiga. Adapun Waktu Perancangan selama 3 (tiga) Bulan mulai dari Februari 2018 sampai dengan Bulan April tahun 2018. Dalam menyelesaikan permasalahan penelitian ini, mengunakan (tiga) metode yaitu : studi literatur, analisis gambar dan persiapan alat kerja dan bahan. Setelah dilakukan pembuatan dan perakitan maka selanjutnya adalah melakukan pengujian terhadap alat kerja. Pengujian dilakukan di SMKN 1 Samatiga pada tanggal 04 april 2018. Adapun data hasil pengujian memperlihatkan bahwa pompa vakum dan pompa hidram berfungsi dengan baik.
\end{abstract}

Kata Kunci : Teknologi irigasi, Pompa hidram, Pompa vakum, Efisiensi dan Laboratorium SMK 1 Sama Tiga.

\section{PENDAHULUAN}

\subsection{Latar Belakang}

Air merupakan salah satu faktor yang sangat penting dan dibutuhkan dalam kehidupan makhluk hidup. Selain untuk pengembangan fisiologis makhluk hidup, air juga menjadi input bagi beragam upaya atau kegiatan makhluk hidup dalam rangka menghasilkan sesuatu untuk kelangsungan hidupnya. Munculnya permasalahan yang menyangkut air yang disebabkan oleh peningkatan beragam kebutuhan serta kepentingan kehidupan makhluk hidup, pada gilirannya berdampak terhadap terganggunya kondisi permintaan dan penyediaan air. Masyarakat membutuhkan air dalam jumlah besar, baik yang berasal dari sumber air permukaan maupun air tanah, sehingga pemanfaatan beragam teknologi yang mampu mengangkat dan mengalirkan air dari sumbernya ke lahan-lahan pertanian serta hunian penduduk sangat dibutuhkan. Oleh karena itu, perlu dicari dan dikembangkan suatu model teknologi irigasi yang memadai, menggunakan teknologi tepat guna, efisien, dan ekonomis sehingga dalam pengelolaannya tidak tergantung pada tenaga 


\section{Jurnal Mekanova \\ Vol 4. No. 6, April 2018 \\ ISSN : 2502-0498}

listrik atau bahan bakar lainnya. Sebuah teknologi yang membutuhkan biaya operasional yang murah dan tidak membebani masyarakat dalam melakukan kegiatan usahanya, salah satu teknologi irigasi yang mulai dikembangkan tersebut adalah pompa hydrolik ram atau lazim disebut pompa hidram.

Dalam perancangan pompa hidram agar mempunyai efisiensi sebaik mungkin di perlukan penelitian terhahap komponen komponen utama pada pompa hidram tersebut. Pada penelitian ini dilakukan pengujian terhadap penggunaan variasi tabung udara dan panjang pipa masuk untuk mendapatkan ukuran volume tabung udara serta panjang pipa pemasukan yang mempunyai efisiensi terbaik. Mengetahui pengaruh tabung udara dan panjang pipa pemasukan terhadap kapasitas serta kinerja dari pompa hidram.

Tujuan Penelitian

Adapun tujuan dari penelitian ini adalah pembuatan pompa hidram yang lebih efektif dan efesien.

Pengertian Umum Pompa

Pompa adalah suatu alat yang digunakan untuk memindahkan suatu cairan dari suatu tempat ke tempat lain dengan cara menaikkan tekanan cairan tersebut. Kenaikan tekanan cairan tersebut digunakan untuk mengatasi hambatan-hambatan pengaliran. Hambatan-hambatan pengaliran itu dapat berupa perbedaan tekanan, perbedaan ketinggian atau hambatan gesek.

Pompa secara umum dapat diklasifikasikan menjadi 2 bagian :

1. Pompa Kerja Positif (Positive Displacement Pump)

Disebut juga dengan pompa aksi positif. Energi mekanik dari putaran poros pompa dirubah menjadi energi tekanan untuk memompakan fluida. Pada pompa jenis ini dihasilkan head yang tinggi tetapi kapasitas yang dihasilkan rendah. Contohnya pompa putar/rotary dan pompa torak/reciprocating.

2. Pompa Sentrifugal (Dynamic Pump / Sentrifugal Pump)

Merupakan suatu pompa yang memiliki elemen utama sebuah motor dengan sudu impeler berputar pada kecepatan tinggi. Fluida yang masuk kemudian dipercepat oleh impeler yang menaikkan kecepatan fluida maupun tekanannya serta melemparkan keluar dari volut. Contohnya pompa sentrifugal.

Jenis-Jenis Pompa

Menurut prinsip dan cara kerjanya, jenis-jenis pompa dibagi kedalam :

1.Pompa Sentrifugal (Centrifugal Pump)

Sifat dari hidrolik adalah memindahkan energi pada daun/kipas pompa dengan dasar pembelokan/pengubah aliran (fluid dynamics). Kapasitas yang di hasilkan oleh pompa sentrifugal adalah sebanding dengan putaran, sedangkan total head (tekanan) yang di hasilkan oleh pompa sentrifugal adalah sebanding dengan pangkat dua dari kecepatan putaran. 


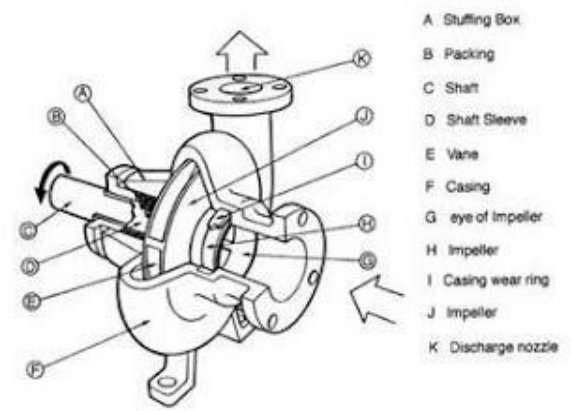

Gambar 1. Pompa Sentrifugal (Centrifugal Pump)

\section{Pompa Desak (Positive Displacement Pumps)}

Kapasitas yang dihasilkan oleh pompa tekan/desak adalah sebanding dengan kecepatan pergerakan atau kecepatan putaran, sedangkan total head (tekanan) yang dihasilkan oleh pompa ini tidak tergantung dari kecepatan pergerakan atau putaran. Contoh pompa desak gerak bolak balik yaitu: pompa piston/plunger pumps, pompa diaphragm pumps.

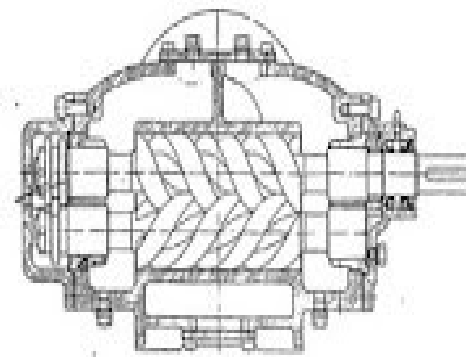

Gebar 4, bertu hape

Gambar 2. Pompa Desak (Positive Displacement Pumps)

\section{Jet pumps}

Sifat dari jets pump adalah sebagai pendorong untuk mengangkat cairan dari tempat yang sangat dalam. Media yang digunakan dapat berupa cairan maupun gas. Pompa ini tidak mempunyai bagian yang bergerak dan konstruksinya sangat sederhana.
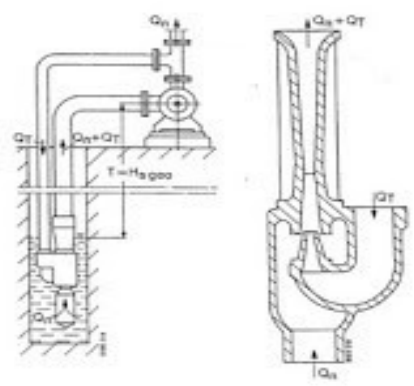

Gambar 3. Jet Pumps

4.Air lift pumps (mammoth pumps) 
Cara kerja pompa ini sangat tergantung pada aksi dari campuran antara cairan dan gas (two phase flow).

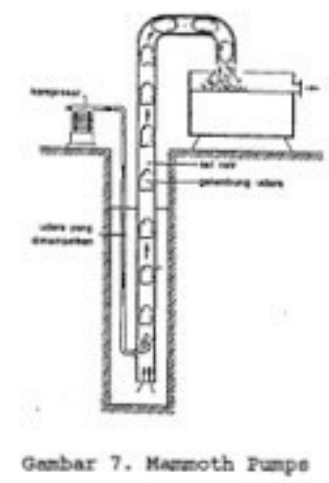

\section{Hidraulic pumps}

Gambar 4. Air lift pumps (mammoth pumps)

Pompa ini menggunakan kinetik energi dari cairan yang dipompakan pada suatu kolom dan energi tersebut diberikan pukulan yang tiba-tiba menjadi energi yang berbentuk lain (energi tekan).
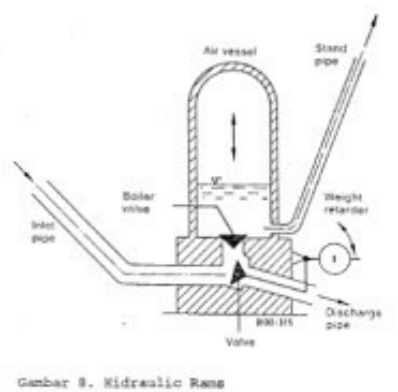

6. Elevator Pump

Gambar 5. Hidraulic pumps

Sifat dari pompa ini mengangkat cairan ke tempat yang lebih tinggi dengan

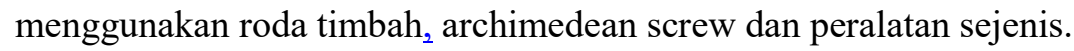

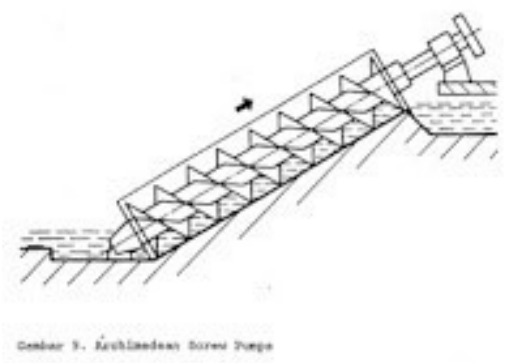

Gambar 6. Elevator Pump

\section{Electromagnetic Pumps}

Cara kerja pompa ini adalah tergantung dari kerja langsung sebuah medan magnet ferromagnetic yang dialirkan, oleh karena itu penggunaan dari pompa ini sangat terbatas pada cairan metal. 


\section{Pompa Hidram}

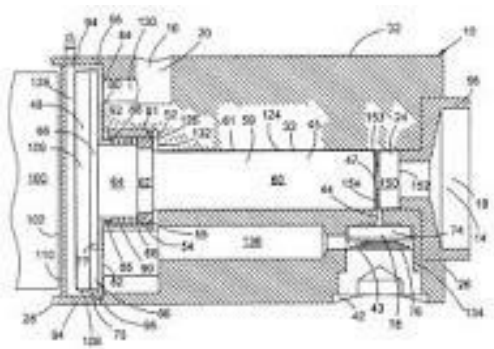

Gambar 7. Electromagnetic Pumps

Pompa hidram merupakan suatu alat yang digunakan untuk menaikkan air dari tempat rendah ke tempat yang lebih tinggi secara otomatik dengan energi yang berasal dari air itu sendiri, karena adanya tinggi air jatuh yang digunakan untuk menekan katup pada pompa hidram sehingga mengakibatkan water hammer.

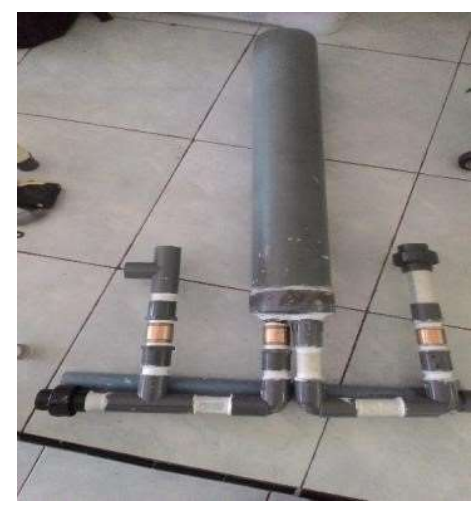

Gambar 8. Pompa Hidram

(Sumber: Penelitian)

Prinsip Kerja Pompa Hidram

Sumber energi pompa hidram berasal dari tekanan tinggi yang diakibatkan adanya fenomena pukulan air (water hammer) dan karena adanya perubahan kecepatan tiba-tiba dari aliran air oleh pada penutupan katup. Pompa ini tidak memerlukan suplai energi dari luar seperti BBM atau listrik.

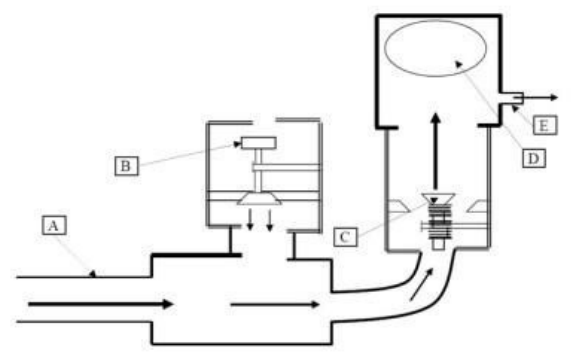

Gambar 9. Prinsip kerja pompa hidram. 


\section{Jurnal Mekanova \\ Vol 4. No. 6, April 2018 \\ ISSN : 2502-0498}

Prinsip kerja dari pompa hidram ini terdapat beberapa komponen seperti pipa suplai (A), katup buang (B), katup masuk (C), tabung udara (D), dan pipa hantar (E). Sistem kerja diawali dengan aliran air dari sumber masuk melalui pipa suplai dan keluar melalui katup buang. Naiknya kecepatan aliran akan mendorong katup buang ke atas hingga tertutup dan menghentikan aliran air dari pipa suplai. Hal ini menyebabkan terjadinya fenomena pukulan air sehingga tekanan naik secara drastis. Kenaikan tekanan ini akan membuka katup masuk sehingga terjadi aliran menuju pipa hantar.

Untuk mendesain pompa hidram perlu dilakukan survei lapangan untuk mendapatkan datadata yang menjadi parameter desain pompa. Beberapa data yang perlu didapatkan adalah :

\section{- Aliran sumber air}

Data ini berupa debit sumber air yang ada pada kondisi normal dan pengukuran harus dilakukan pada musim kering karena pada saat itulah terjadi debit minimum.

- Head air suplai

Dengan melihat sejauh mana ketinggian sumber air terhadap lokasi pompa hidram dan kemiringan lokasi di bawah sumber air.

- Head penampung

Tinggi dari sumber air ke tempat yang diharapkan untuk suplai air perlu diketahui untuk memperkirakan penempatan pompa hidram.

\section{- Kebutuhan air}

Ini diestimasi berdasarkan populasi penduduk atau luas lahan pertanian yang akan dilayani atau kebutuhan lainnya sesuai dengan kondisi tiap-tiap daerah.

Keuntungan Pompa Hidram

Ada beberapa keuntungan menggunakan pompa hidram, antara lain:

1.Hemat energi

2. Tidak membutuhkan energi listrik

3. Mudah dibuat

4.Bisa digunakan di tempat terpencil yang tidak terjangkau listrik

\section{METODE PENELITIAN}

\subsection{Tempat Dan Waktu Pelaksanaan}

Penelitian ini dilakukan di Laboratorium SMK 1 Sama Tiga. Adapun Waktu Perancangan selama 3 (tiga) Bulan mulai dari Februari 2018 sampai dengan Bulan April tahun 2018.

\subsection{Metode Pengumpulan Data}

Dalam menyelesaikan masalah, diperlukan data-data untuk penyusunan penelitian ini, antara lain:

a. Studi Literatur

Melalui buku-buku pedoman yang berkaitan dengan penelitian dan melalui laman-laman website sebagai penunjang.

b. Analisa Gambar

Menganalisa gambar terhadap proses pengerjaan penelitian. 
c.Persiapan Alat Kerja dan Bahan

Menyediakan peralatan kerja yang digunakan sesuai dengan kebutuhan yang diperlukan. Bahan yang Digunakan

Adapun bahan-bahan yang digunakan dapat dilihat pada tabel 1 berikut ini:

Tabel 1. Bahan yang digunakan

\begin{tabular}{|c|l|c|c|c|c|}
\hline No & \multicolumn{1}{|c|}{ Uraian } & Spesifikasi & Volume & Satuan & Keterangan \\
\hline 1. & Kawat Las & RB 25 & 1 & Kg & \\
\hline 2. & Mata Gerinda potong & $8 \& 16$ inch & 2 & Buah & \\
\hline 3. & Plat strep & $2 \mathrm{~mm} \times 2 \mathrm{~cm}$ & 5 & Meter & \\
\hline 4. & Besi Siku & $40 \times 40 \times 6$ & 2 & Batang & \\
\hline 5. & Cat Alvian & & 1 & Liter & \\
\hline 6. & Thinner & & 2 & Liter & \\
\hline 7. & Pipa PVC & 4 inch & 75 & Meter & \\
\hline 8. & Shock drat luar & 1 inchi & 8 & Buah & \\
\hline 9. & Shock drat dalam & 1 inchi & 2 & Buah & \\
\hline 10. & Shock T & 1 inchi & 2 & Buah & \\
\hline 11. & Water Mur & 1 inchi & 2 & Buah & \\
\hline 12. & Seal Tape & & 4 & Buah & \\
\hline 13. & Lem power glue & & 1 & Kaleng & \\
\hline 14. & Valve & 1 inchi & 4 & Buah & \\
\hline 15. & Valve & $3 / 4$ inchi & 1 & Buah & \\
\hline 12. & Drum & Bulat & 2 & Buah & \\
\hline
\end{tabular}

Diagram Alir Pembuatan

Flowchart pembuatan pompa hidram dapat dilihat pada gambar dibawah ini: 


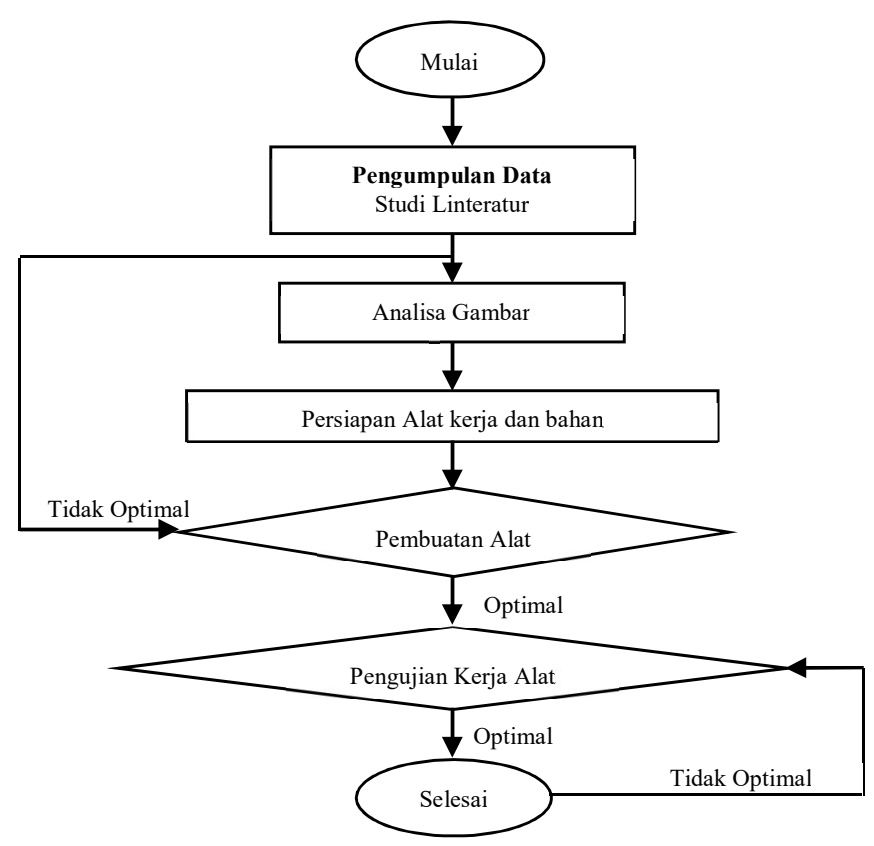

Gambar 10. Flowchat Penelitian

III. HASIL DAN PEMBAHASAN

Hasil Pembuatan Kombinasi Pompa Vakum Dengan Pompa Hidram

Langkah pembuatan kombinasi pompa vakum dengan pompa hidram seperti dibawah ini: 1.Pembuatan tabung vakum

Pembuatan tabung vakum menggunakan drum, yang kemudian pada sisi atas dan bawah dilubangi.

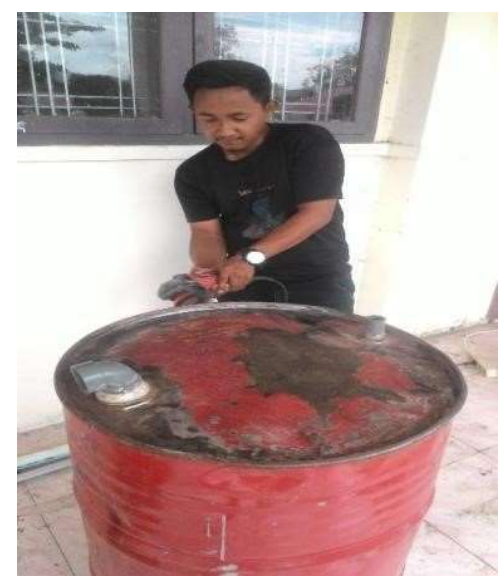

Gambar 11. Tabung pompa vakum

2.Pembuatan kerangka pompa vakum

Pembuatan kerangka pompa vakum ini menggunakan plat strep $2 \mathrm{~mm} \times 2 \mathrm{~cm}$ dan besi siku dengan ukuran 40x40x6, yang kemudian dilakukan penyambungan atau pembentukan dengan proses pengelasan yang sesuai dengan bentuk. 


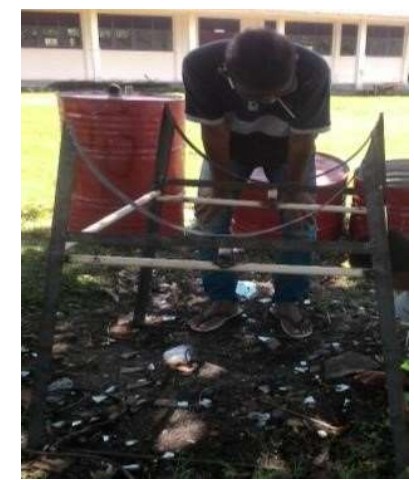

Gambar 12. Pengerjaan rangka dasar

Pembuatan kerangka pompa hidram

Pembuatan kerangka pompa hidram menggunakan bahan pipa yaitu: Pipa PVC, Shock drat luar, Shock drat dalam, Shock T, Water Mur, Valve, Seal Tape, Lem power glue.

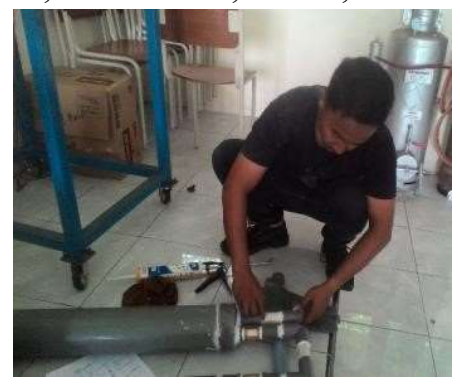

Gambar 13. Pembuatan kerangka pompa hidram

Pengecatan

Pengecatan adalah suatu langkah yang membuat alat tersebut terhindar dari korosi, juga memperindah suatu alat yang dibuat.

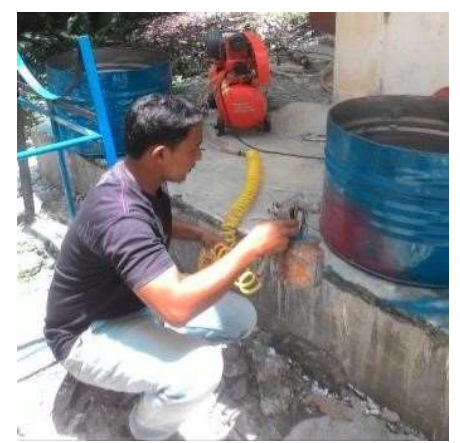

Gambar 14. Proses pengecatan

Pengujian pompa vakum dan pompa hidram

Setelah dilakukan pembuatan dan perakitan maka selanjutnya adalah proses pengujian terhadap kerja alat. Pengujian dilakukan di SMKN 1 Samatiga. 


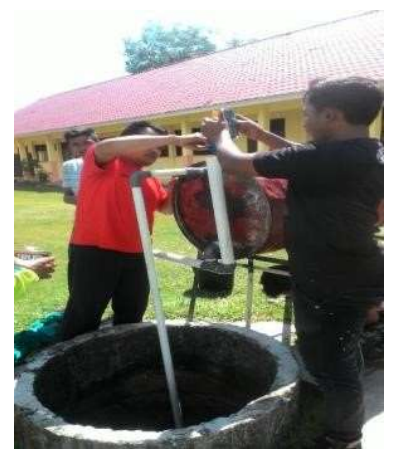

Data Hasil Pengujian

Gambar 15. Pengujian pompa vakum dan pompa hidram

Adapun data hasil pengujian dapat dilihat pada tabel 2 berikut:

Tabel 2. Data Hasil Pengujian

(Sumber: Penelitian)

\begin{tabular}{|c|l|c|}
\hline No & \multicolumn{1}{|c|}{ Uraian } & Keterangan \\
\hline 1 & Pompa Vakum & Berfungsi dengan baik \\
\hline 2 & Pompa Hidram & Berfungsi dengan baik \\
\hline
\end{tabular}

\section{KESIMPULAN}

1. Pengaruh ketinggian pompa vakum dapat mempengaruhi proses penghisapan air dari sumber air serta dapat mempengaruhi tekanan/dorongan pada klep pompa.

2. Besarnya tabung pompa vakum dapat mempengaruhi tekanan aliran air.

3. Pompa vakum dan pipa penghisap air dari sumber air tidak boleh terjadi kebocoran.

\section{SARAN}

Teknologi pompa vakum dengan pompa hidram yang cukup sederhana, diharapkan dapat diaplikasikan oleh masyarakat untuk memenuhi kebutuhan air bersih maupun untuk keperluan yang lainnya.

\section{DAFTAR PUSTAKA}

[1]. Handojo, Dr.Ir.Lienda, M.Eng. 1995. Teknologi Kimia. PT Pertja. Jakarta

[2]. Ismail, Syarifuddin. Alat Industri Kimia. Universitas Sriwijaya. Palembang

[3]. Margaretty. Elina, Rusnadi. Irawan, Suci Ningsih. Aisyah. 2012. Modul Peralatan Industri

[4]. http://mangihot.blogspot.co.id/2016/12/pompa.html

[5]. https://berandainovasi.com/pompa-hidram/

[6]. http://www.kelair.bppt.go.id/sitpapdg/Patek/Hidran/hidran.html

[7]. https://projectmedias.blogspot.co.id/jenis pompa 